\title{
Associação entre concentrações séricas de minerais, índices antropométricos e ocorrência de diarréia entre crianças de baixa renda da região metropolitana do Rio de Janeiro
}

\author{
Association among serum concentration \\ of minerals, anthropometric indices and diarrhea \\ in low-income children in the metropolitan region of \\ Rio de Janeiro, Brazil
}

\author{
Cássia Viviane Dantas BORGES 1 \\ Ana Paula Black VEIGA' \\ Gabriela dos Santos BARROSO ${ }^{1}$ \\ Edgar Francisco Oliveira de JESUS² \\ Renata Faria Barbosa SERPA ${ }^{3}$ \\ Silvana MOREIRA ${ }^{4}$ \\ Rosana SALLES-COSTA 5
}

RES U M O

\section{Objetivos}

Avaliar a associação entre concentrações séricas de ferro, zinco e cobre, perfil nutricional e ocorrência de diarréia entre crianças residentes em uma comunidade de baixa renda no município de Duque de Caxias, Rio de Janeiro, Brasil.

\section{Métodos}

Trata-se de um estudo transversal, que avaliou 104 crianças, na faixa etária de 1 a 5 anos, selecionadas entre os meses de abril a dezembro de 2004, pelo projeto Vila Rosário. Avaliou-se o perfil socioeconômico das

\footnotetext{
1 Universidade Federal Fluminense, Curso de Nutrição. Rio de Janeiro, RJ, Brasil.

${ }^{2}$ Universidade Federal do Rio de Janeiro, Escola de Engenharia, Departamento de Engenharia Nuclear. Rio de Janeiro, RJ, Brasil.

${ }^{3}$ Universidade Federal do Rio de Janeiro, Centro de Tecnologia. Rio de Janeiro, RJ, Brasil.

${ }^{4}$ Universidade Estadual de Campinas, Departamento de Saneamento e Ambiente. Campinas, SP, Brasil.

5 Universidade Federal do Rio de Janeiro, Instituto de Nutrição, Departamento de Nutrição Social e Aplicada. Av. Brigadeiro Trompwsky, s/n, CCS Bloco J, $2^{\circ}$ andar, Ilha do Fundão, 21941-590, Rio de Janeiro, RJ, Brasil. Correspondência para/Correspondence to: R. SALLES-COSTA. E-mail: <rosana_salles@terra.com.br>.
} 
160 | C.V.D. BORGES et al.

famílias e de saúde das crianças, incluindo a ocorrência de diarréia. A avaliação nutricional incluiu peso, estatura/comprimento, índices peso-para-idade e estatura-para-idade, expressos em escores-Z e classificação do estado nutricional segundo estes índices. As concentrações séricas de zinco, ferro e cobre foram determinados em uma sub-amostra $(n=59)$ a partir da técnica de florescência de raios x por reflexão total com radiação síncroton.

\section{Resultados}

As crianças residiam em domicílios caracterizados por condições sanitárias insatisfatórias, com famílias numerosas e com baixo poder aquisitivo. A prevalência de diarréia no último mês foi de 55,7\%. Cerca de $28,4 \%$ das crianças apresentaram déficit ponderal e 4,9\% delas déficit estatural. A deficiência de ferro, zinco e cobre encontrada na amostra foi de, respectivamente, 13\%, 7,5\% e 8,9\%. Não foi observada associação significante entre os indicadores do perfil nutricional e os valores séricos dos minerais. As crianças com relato de diarréia apresentaram valores séricos médios de minerais inferiores aos daquelas sem relato, sendo significante para os valores de zinco.

\section{Conclusão}

As crianças com episódios de diarréia podem apresentar comprometimento das concentrações séricas de zinco.

Termos de indexação: antropometrica; deficiência de minerais; diarréia; zinco.

\section{A B S T R A C T}

\section{Objective}

The objective of this study was to evaluate the association among blood serum concentrations of iron, zinc, copper, nutritional status and occurrence of diarrhea in children from a low-income community in Duque de Caxias, Rio de Janeiro.

\section{Methods}

This is a cross-sectional study that evaluated 104 children aging from 1 to 5 years, selected in the months of April and December 2004, by the project Vila Rosário. The socioeconomic profile of the families and health of the children were assessed, including the occurrence of diarrhea. Nutritional assessment included weight, height/length, weight-for-age and height-for-age indices expressed in Z-scores and classification of the nutritional status based on these indices. Serum concentrations of zinc, iron and copper were determined in a sub-sample $(n=59)$ by synchrotron total reflection $x$-ray fluorescence.

\section{Results}

The children lived in crowded households with unsatisfactory sanitary conditions and were from low-income families. The prevalence of diarrhea in the last moth was $55.7 \% ; 28.4 \%$ of the children were underweight and $4.9 \%$ were stunted. Iron, zinc and copper deficiencies in the sample were $13.0 \%, 7.5 \%$ and $8.9 \%$ respectively. There was no significant association between nutritional indicators and serum concentration of the minerals. Blood serum levels of zinc in children without diarrhea were significantly higher than among those with diarrhea.

\section{Conclusion}

Episodes of diarrhea can compromise blood serum levels of zinc in children.

Indexing terms: anthropometry; micronutrient deficiency; diarrhea; zinc.

\section{N T R O D U ÇÃ O}

As crianças constituem um dos grupos mais vulneráveis da população, uma vez que estão expostas a altos riscos de saúde durante o seu crescimento ${ }^{1}$. A nutrição adequada é um dos fatores de maior impacto na saúde infantil, ressaltando que o déficit nutricional é responsável, direta ou indiretamente, por mais de $60 \%$ das 10 milhões de mortes que acometem crianças menores de cinco anos de idade, causadas, em sua maior parte, por doenças infecciosas, como a diarréia'. 
Ao longo das últimas décadas, o Brasil sofreu marcantes modificações políticas, econômicas e sociais, que contribuíram consideravelmente para beneficiar o perfil nutricional da população infantil, bem como as suas condições de saúde ${ }^{2}$. No entanto, poucos são os estudos conduzidos relacionando o perfil de micronutrientes e saúde nesse grupo no Brasil. Em 2003, o Fundo das Nações Unidas para a Infância (UNICEF) ${ }^{3}$ destacou que a deficiência de micronutrientes (vitaminas e minerais) foi umas das grandes responsáveis por cerca de um milhão de óbitos entre crianças, devido ao acometimento do sistema imune, além de contribuir para o prejuízo mental de mais de 100 milhões, e para, aproximadamente, 250 mil nascimentos de crianças com sérios defeitos, anualmente.

Entre as deficiências de micronutrientes, a anemia ferropriva, principal marcador da deficiência de ferro, é um importante problema de saúde pública, afetando, aproximadamente, dois bilhões de pessoas ${ }^{4}$, contribuindo para a morbidade e mortalidade de crianças ${ }^{5}$, destacando-se como o mais freqüente problema carencial do País, conforme Batista Filho \& Rissin².

A deficiência marginal de zinco é um problema nutricional comum, principalmente em países em desenvolvimento, acreditando-se que sua existência, mesmo não associada a uma característica clínica específica, já produziria sérias conseqüências para a saúde infantil ${ }^{6,7}$. Cerca de 800 mil mortes de crianças por ano são atribuídas à deficiência de zinco ${ }^{4}$.

O papel do zinco no crescimento ${ }^{8,9}$ e no sistema imunológico, principalmente na redução de infecções, como pneumonia e diarréia, vem sendo investigado ${ }^{10,11}$. Em relação à diarréia, tem sido bem documentada a influência do zinco no seu tratamento, pela diminuição dos episódios diarréicos, assim como da severidade da diarréia ${ }^{12,13}$. O papel do zinco no desenvolvimento cognitivo também tem sido descrito, ressaltando a importância da adequação dietética na infância ${ }^{11}$.
O papel do cobre na saúde infantil também se mostra relevante. O cobre é essencial para formação de hemoglobina e células vermelhas, na formação de tecido conjuntivo (que engloba formação óssea e mineralização esquelética, integridade do tecido no coração e no sistema vascular), de melanina, para o sistema nervoso central (na formação e manutenção da mielina e para neurotransmissão normal), para a função cardíaca, entre outras ${ }^{14,15}$. Evidências recentes indicam sua influência na função imunológica, bem como no tratamento da diarréia, associado à suplementação de zinco ${ }^{16}$.

Apesar da importância da avaliação sérica de micronutrientes na infância, são escassos os estudos avaliando a prevalência das deficiências desses minerais. Atualmente, alguns trabalhos associando as concentrações séricas de ferro, zinco e cobre, com o estado nutricional são realizados em países da África e Ásia. No Brasil, são poucos os estudos publicados avaliando o perfil bioquímico de minerais, sendo destacada, com maior freqüência, a alta prevalência de anemia nos primeiros anos de vida ${ }^{17}$.

A técnica de Fluorescência de Raios X por Reflexão Total com Radiação Síncrotron (SR-TXRF) é uma ferramenta extremamente útil na determinação dos teores de minerais em diversos tipos de amostras, como água, solo, soro, plasma, e até mesmo o próprio sangue, e que, recentemente, tem sido utilizada em estudo com animais e seres humanos ${ }^{18,19}$. A possibilidade de determinação simultânea de vários elementos com uma pequena quantidade de amostra, é uma de suas vantagens sobre outros métodos ${ }^{18-20}$. Nenhum trabalho, até então, foi encontrado na literatura utilizando esta técnica para avaliação do estado de minerais em crianças.

O objetivo deste estudo foi avaliar a associação entre o perfil nutricional, concentrações séricas de ferro, zinco e cobre, determinados pela técnica de SR-TXRF, e ocorrência de diarréia entre crianças residentes em uma comunidade de baixa renda no município de Duque de Caxias, no Rio de Janeiro. Este estudo está inserido no projeto 
denominado "Vila Rosário", que consiste em estabelecer um modelo integrado, multi e interdisciplinar, com o objetivo de promover a reabilitação social desta comunidade, sendo os resultados desta pesquisa uma base inicial para futuras intervenções, pois não há registro de estudo similar desenvolvido na região.

\section{MÉ T O D OS}

O Município de Duque de Caxias localiza-se na Região Metropolitana do Estado do Rio de Janeiro, cuja sede municipal está situada a $27 \mathrm{~km}$ de distância da capital. A comunidade de Vila Rosário encontra-se no segundo distrito de Duque de Caxias e corresponde a uma das áreas mais carentes do município, composta por vários bairros de características urbanas e rurais ${ }^{21}$. Um documento recentemente apresentado no "Seminário Especial sobre Fome e Pobreza", realizado no Rio de Janeiro, demonstrou que cerca de $14,5 \%$ da população residente no Município de Duque de Caxias vive abaixo da linha de pobreza extrema para o Estado do Rio de Janeiro, ocupando o sétimo lugar entre os municípios de proporções mais elevadas, o que corresponde a quase o dobro da proporção média do Estado $(8,6 \%)^{22}$.

Trata-se de um estudo transversal, realizado em uma amostra de 104 crianças na faixa etária de 1 a 5 anos, de ambos os sexos, residentes na comunidade de Vila Rosário, no município de Duque de Caxias, RJ. A amostra foi formada pelo total de crianças atendidas no projeto Vila Rosário, entre os meses de abril a dezembro de 2004. As crianças que apresentaram acompanhamento nutricional e/ou clínico em outra unidade de saúde, portadoras de doenças crônicas, e as que não residiam na área de Vila Rosário, não foram selecionadas para o estudo.

A coleta de dados foi realizada no Ambulatório Paroquial Irmã Beta (ASPAS), que atende a comunidade de Vila Rosário, e contou com a participação de uma equipe treinada, composta por nutricionistas e agentes comunitários. $\mathrm{Na}$ primeira consulta da criança no projeto, foi aplicado um questionário contendo perguntas referentes a identificação, perfil de saúde, além da realização do exame antropométrico. A criança era encaminhada para uma nova consulta, para avaliação por questionário socioeconômico e exames bioquímicos, no prazo máximo de duas semanas. Esta pesquisa foi aprovada pela Comissão de Ética e Pesquisa do Instituto de Pediatria e Puericultura Martagão Gesteira (IPPMG) da Universidade Federal do Rio de Janeiro (UFRJ), em 25 de setembro de 2003, como parte do projeto "Associação entre perfil nutricional e perfil clínico, de crianças desnutridas em uma comunidade de baixa renda com incidência elevada de tuberculose no município de Duque de Caxias, RJ".

\section{Avaliação antropométrica}

O exame antropométrico incluiu as medidas de peso e estatura/comprimento. Para as crianças menores de 2 anos de idade, o peso foi aferido utilizando uma balança digital do tipo "pesa-bebê", da marca "Filizola", com variação de 1 grama, sendo a criança pesada sentada ou deitada, sem roupa e acessórios. O comprimento foi aferido com auxílio de um infantômetro, sendo a leitura obtida com o lactente deitado em um colchão próprio, com a cabeça posicionada próxima à prancha imóvel, mantendo-se a criança paralela à régua, com os joelhos pressionados para permanecerem estendidos, e os pés juntos formando com os tornozelos um ângulo de $90^{020}$. Para as crianças maiores, o peso foi coletado utilizando uma balança antropométrica, digital, da marca "seca alpha", com variação em 10 gramas, sendo a criança pesada em pé, sem roupas pesadas, sapatos e acessórios. Para estatura, foi utilizada uma fita métrica fixa à parede, sendo a criança posicionada ereta, na mesma direção da fita, com calcanhares e glúteos juntos à parede, com braços paralelos e relaxados, posicionando a cabeça de forma que o plano de Frankfort ficasse paralelo ao chão, sendo a leitura feita com o auxílio de um esquadro de madeira ${ }^{23}$. 
As crianças foram avaliadas segundo os índices antropométricos peso para idade $(\mathrm{P} / \mathrm{I})$ e estatura para idade (E/I), de acordo com o sexo, sendo os indicadores expressos em escore-Z, utilizando as curvas do National Center for Health Statistics (NCHS) e do Center for Diseases Control and Prevention (CDC), 2000, como distribuição de referência. As crianças classificadas como eutróficas foram aquelas cujos índices E/I e P/I foram superiores a $-2,0$ escores- $Z$, e com déficit ponderal (P/I) e/ou estatural (E/I), respectivamente, aquelas com valores de escore- $Z$ iguais ou inferiores $a-2,0^{24}$.

\section{Avaliação Bioquímica}

A coleta de sangue foi realizada por auxiliar de enfermagem treinado, no prazo de até um mês após a primeira avaliação da criança (admissão no projeto). Foram coletados, no máximo, $5 \mathrm{~mL}$ de sangue para cada criança. O sangue foi transportado do ambulatório da ASPAS para o Instituto de Nutrição da UFRJ, acondicionado em isopor com gelo, onde foi centrifugado a 3.500 rpm por, aproximadamente, 5 minutos ou o tempo suficiente para separação do soro. Após, o soro foi armazenado em ependorfs no freezer a $-18^{\circ} \mathrm{C}$. Em média, o tempo de armazenamento foi inferior a 12 meses.

Para determinação dos valores séricos de ferro, zinco e cobre, foi utilizada a Técnica de Fluorescência de Raios X por Reflexão Total com Radiação Síncrotron (SR-TXRF), no Laboratório Nacional de Luz Síncrotron, em Campinas, São Paulo, em colaboração com o Laboratório de Instrumentação Nuclear da Universidade Federal do Rio de Janeiro. Para um maior controle das concentrações determinadas, foi utilizado um padrão certificado de água da Merck (P1), que possui quantidades certificadas de vários elementos, e pela determinação desses elementos foi possível aferir a precisão da técnica e garantir a consistência dos dados.

As crianças que apresentaram valores séricos de ferro inferiores a $60 \mu \mathrm{g} / \mathrm{dL}$, foram consideradas com deficiência ${ }^{25}$, para o zinco valores inferiores a $65 \mu \mathrm{g} / \mathrm{dL}^{26}$, e para o cobre valores abaixo de $90 \mu \mathrm{g} / \mathrm{dL}^{27}$.

\section{Avaliação do perfil de saúde e indica- dores socioeconômicos}

Foi aplicado um questionário contendo perguntas referentes à saúde da criança (idade, peso ao nascer, internações recentes, ocorrência de parasitoses e diarréia) e também ao perfil materno (idade do responsável, idade na primeira gravidez, número de filhos), o qual foi pré-testado em estudo piloto com crianças apresentando as mesmas características desta população de estudo. Foram avaliadas, também, informações quanto às condições de moradia, constituição familiar, renda familiar, por meio da aplicação de questionário socioeconômico.

A ocorrência de diarréia foi considerada quando a criança apresentou 4 ou mais episódios de evacuações líquidas ou semilíquidas ao dia, durante o mês anterior à sua primeira participação ou consulta no projeto.

\section{Análise estatística}

Inicialmente, realizou-se análise exploratória dos dados, por meio de análise gráfica, estimativas das freqüências, das médias e desvios-padrão. Estimaram-se o coeficiente de correlação de Pearson, para avaliar a associação entre as concentrações séricas de ferro, zinco e cobre, e os valores de escores-Z para os índices $\mathrm{P} / \mathrm{I}$ e E/l, considerando o nível de significância de $5 \%$. 0 teste " $t$ "-Student foi utilizado para comparar as médias das concentrações séricas de ferro, zinco e cobre entre crianças com ocorrência ou ausência de episódio de diarréia no mês anterior à primeira consulta, e entre crianças com ou sem fornecimento de água canalizada no domićlio.

O banco de dados foi elaborado e digitado pela equipe de pesquisadores, no programa Epi Info 6.04 e todos os procedimentos de análise 
realizados no programa Stata 8.0 (2002), sendo a classificação antropométrica realizada no Epi Info 2000.

\section{RESULTADOS}

Das 104 crianças avaliadas, foram analisados 65 questionários socioeconômicos e 59 exames bioquímicos. As perdas referentes à avaliação dos questionários socioeconômicos $(37,5 \%, n=39)$ ocorreram pelo não retorno da criança às consultas subseqüentes. As perdas bioquímicas $(n=45)$, cerca de $69,0 \%(n=31)$, foram decorrentes do não retorno ao ambulatório e $8,9 \%(n=14)$ devido a problemas no transporte para Campinas (para análise pelo TXRF-SR). Foram excluídos, ainda, das análises de cada mineral, valores considerados extremos (outliers) na distribuição de dados (ferro $-n=5$; zinco $-n=6$; cobre - $n=3$ ).

Na Tabela 1 observa-se que quase a totalidade dos responsáveis não atingiu 9 anos de estudo, ressaltando que nenhum deles referiu ter freqüentado o ensino superior. Quanto às condições higiênico-sanitárias dos domicílios, cerca de $25 \%$ das famílias usufruíram da rede pública de abastecimento de água e mais da metade não tinha sistema de esgoto. Apesar de, aproximadamente, 54\% dos domicílios usarem filtro de água, um percentual elevado de famílias não tratavam a água para o consumo. Em relação à estrutura familiar, encontraram-se famílias numerosas, com mais de 5 moradores por domicílio, com menos de 1 cômodo por morador e com renda familiar per capita representando cerca de 15\% do salário mínimo atual. Apesar de a idade média dos responsáveis ter sido, aproximadamente, de 31 anos, as mães iniciaram a maternidade precocemente, por volta dos 18 anos, apresentando uma média superior a 3 filhos.

As crianças apresentaram uma média de idade aproximada de 30 meses. A média de peso ao nascer foi superior a 2.500 gramas, mostrando-se dentro da normalidade, apesar de $17,0 \%$ das crianças terem nascido com baixo peso. A média dos valores de escore-Z para os índices P/l e E/I apresentou-se negativa, mostrando tendência das crianças ao déficit nutricional. A prevalência de déficit ponderal e estatural foi, respectivamente, $28,4 \%(n=29)$ e $4,9 \%(n=5)$ (Tabela 2$)$, observa-se, também, que os valores médios para as concentrações séricas de ferro, zinco e cobre revelaram-se normais, de acordo com as referências utilizadas

Tabela 1. Distribuição percentual e valores médios (M) com respectivos desvios-padrão (DP) das características socioeconômicas e maternas das famílias da população de estudo. Duque de Caxias, Rio de Janeiro, 2005.

\begin{tabular}{|c|c|c|}
\hline Variáveis socioeconômicas & $\%$ & $n^{1}$ \\
\hline \multicolumn{3}{|l|}{ Escolaridade do responsável } \\
\hline Sem instrução & 3,3 & 2 \\
\hline 1 a 3 anos de estudo & 13,1 & 8 \\
\hline 4 a 5 anos de estudo & 29,5 & 18 \\
\hline 6 a 9 anos de estudo & 45,9 & 28 \\
\hline 10 a 12 anos de estudo & 8,2 & 5 \\
\hline \multicolumn{3}{|l|}{ Situação conjugal do responsável } \\
\hline Casado/União & 70,8 & 46 \\
\hline Separado/Viúvo & 13,8 & 9 \\
\hline Solteiro & 15,4 & 10 \\
\hline \multicolumn{3}{|l|}{ Água canalizada } \\
\hline Não & 24,6 & 16 \\
\hline Sim, em pelo menos 1 cômodo & 49,2 & 32 \\
\hline Sim, do lado externo da propriedade & 26,2 & 17 \\
\hline \multicolumn{3}{|l|}{ Esgoto canalizado $(n=59)$} \\
\hline Não & 66,1 & 39 \\
\hline \multicolumn{3}{|l|}{ Filtro de água } \\
\hline Sim & 53,8 & 35 \\
\hline Não, mas a água é tratada para beber & 15,4 & 10 \\
\hline Não tem filtro e nem trata água & 30,8 & 20 \\
\hline \multicolumn{3}{|l|}{ Renda familiar per capita (em reais) ${ }^{2}$} \\
\hline Até 24,00 & 32,8 & 22 \\
\hline $25,00-43,00$ & 29,9 & 20 \\
\hline \multirow[t]{2}{*}{43,00 ou mais } & 37,3 & 25 \\
\hline & $\mathrm{M}$ & $\mathrm{DP}$ \\
\hline Moradores por domícilo $(n=65)^{1}$ & 5,6 & 1,80 \\
\hline Números de cômodos por morador & 0,6 & 0,90 \\
\hline Idade responsável (anos) $(n=64)^{1}$ & 31,3 & 11,30 \\
\hline Idade da mãe na $1^{\text {a }}$ gestação $(n=95)^{1}$ & 18,8 & 4,19 \\
\hline Número de filhos $(n=101)^{1}$ & 3,36 & 1,76 \\
\hline
\end{tabular}


Em valores percentuais, $13,0 \%$ das crianças $(n=7)$ apresentaram deficiência de ferro, 7,5\% $(n=4)$ deficiência de zinco e 8,9\% (n=5) deficiência de cobre.

Quanto ao histórico de internações e doenças, cerca de $30,0 \%$ das crianças sofreu alguma internação no último ano, a maioria delas por doenças do aparelho respiratório, ressaltando que mais da metade da amostra apresentou episódio de diarréia no último mês (Tabela 2).

Nas Figuras 1 e 2 verifica-se a distribuição dos valores de escore-Z das crianças para os índices E/I (Figura 1) e P/I (Figura 2). É possível constatar um desvio para a esquerda em ambas as distribuições, o que sugere uma tendência para o déficit estatural (Figura 1) e ponderal (Figura 2) na amostra avaliada.

Nas correlações entre os teores séricos e os valores de escore-Z para P/l e E/I, não foi observada significância estatística entre as variáveis $(p>0,05)$.

Tabela 2. Valores médios (M) com respectivos desvios-padrão (DP) e distribuições percentuais das variáveis referentes ao perfil de saúde das crianças avaliadas. Duque de Caxias, Rio de Janeiro, 2005.

\begin{tabular}{|c|c|c|}
\hline Variáveis & M & DP \\
\hline Idade (meses) $(n=104)^{1}$ & 30,80 & 14,00 \\
\hline Peso ao nascer $(g)(n=88)^{1}$ & 2986,60 & 488,20 \\
\hline Escore-Z para $P / I(n=102)^{1}$ & $-1,66$ & 0,97 \\
\hline Escore-Z para E/I $(n=102)^{1}$ & $-0,67$ & 0,80 \\
\hline Ferro sérico $(\mu \mathrm{L} / \mathrm{dL})(\mathrm{n}=53)^{1}$ & 180,75 & $118,37(2,59)^{2}$ \\
\hline Zinco sérico $(\mu \mathrm{L} / \mathrm{dL})(\mathrm{n}=53)^{1}$ & 137,00 & $51,75(1,72)^{2}$ \\
\hline \multirow[t]{2}{*}{ Cobre sérico $(\mu \mathrm{L} / \mathrm{dL})(\mathrm{n}=56)^{1}$} & 147,22 & $41,0(2,21)^{2}$ \\
\hline & $\%$ & $n^{1}$ \\
\hline $\begin{array}{l}\text { Crianças nascidas com baixo peso } \\
(<2.500 \mathrm{~g})\end{array}$ & 17,0 & 14 \\
\hline Déficit ponderal (segundo o índice $\mathrm{P} / \mathrm{I}$ ) & 28,4 & 29 \\
\hline Déficit estatural (segundo o índice E/I) & 4,9 & 5 \\
\hline$N^{\circ}$ de internações no último ano & 29,9 & 29 \\
\hline Doenças do aparelho respiratório & 69,0 & 21 \\
\hline \multicolumn{3}{|l|}{ Histórico de Doenças } \\
\hline Ocorrência de parasitoses intestinais & 47,1 & 49 \\
\hline Episódio de diarréia no último mês & 55,7 & 58 \\
\hline
\end{tabular}

1 Os valores diferem do total devido às perdas em cada categoria de análise; ${ }^{2}$ Valores médios referentes aos desvios-padrão para as três leituras de cada amostra.
Na Tabela 3, observa-se que para as crianças com relato de diarréia no período, as concentrações médias de zinco foram significantemente menores $(p<0,05)$ do que aquelas sem relato. Apesar de as demais médias terem sido menores para os outros minerais, as diferenças não foram significantes. Observa-se, ainda, uma tendência de valores menores de zinco e ferro entre as crianças com ausência de água canalizada no domicílio.

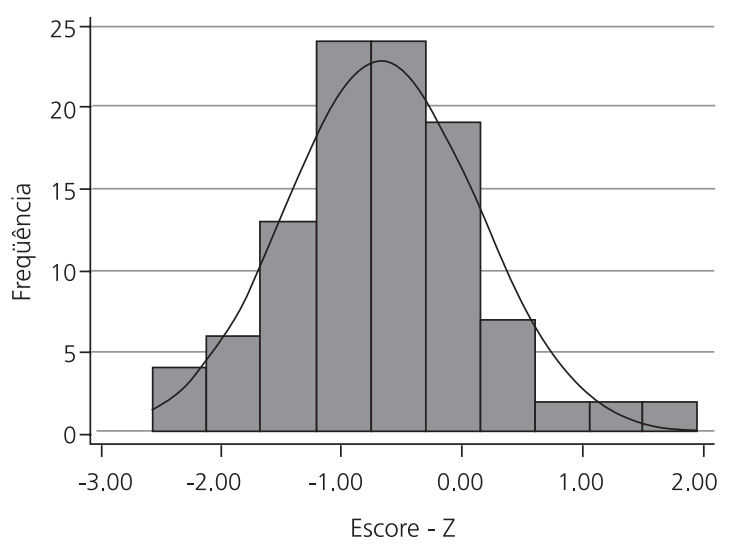

Figura 1. Histograma dos valores de escores-Z da amostra para o índice estatura para idade ( $E / l(n=102)$. Duque de Caxias, Rio de Janeiro, 2005.

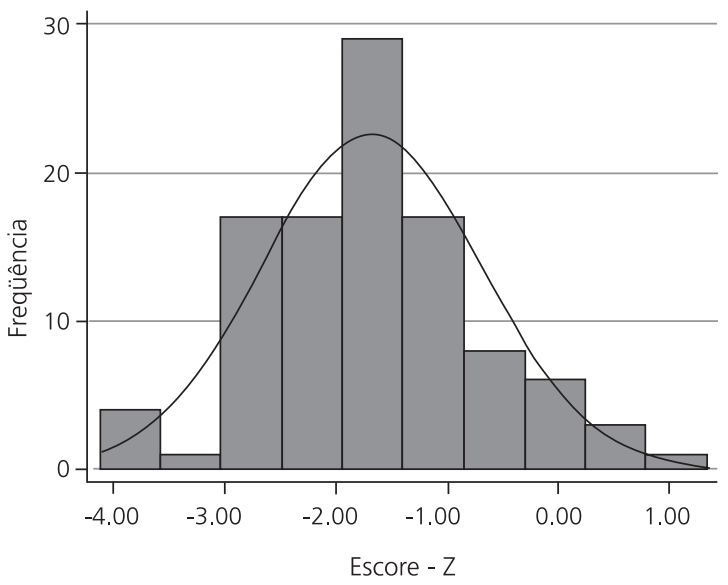

Figura 2. Histograma dos valores de escore-Z da amostra para o índice peso para idade $(P / I)(n=102)$. Duque de Caxias, Rio de Janeiro, 2005. 
Tabela 3. Comparação de médias referentes a diarréia, água canalizada, e às concentrações séricas de ferro, zinco e cobre em uma amostra de crianças de Vila Rosário. Duque de Caxias, Rio de Janeiro, 2005.

\begin{tabular}{|c|c|c|c|c|c|c|}
\hline & \multicolumn{3}{|c|}{$\begin{array}{l}\text { Referiu diarréia } \\
\text { no último mês }\end{array}$} & \multicolumn{3}{|c|}{$\begin{array}{c}\text { Não referiu diarréia } \\
\text { no último mês }\end{array}$} \\
\hline & $n$ & $M$ & DP & $n$ & $M$ & DP \\
\hline Ferro & 33 & 174,54 & 133,58 & 21 & 190,22 & 92,84 \\
\hline Zinco & 30 & 124,92 & 42,58 & 23 & 154,99 & $58,34^{1}$ \\
\hline \multirow[t]{2}{*}{ Cobre } & & 139,89 & 38,98 & 23 & 157,74 & 42,38 \\
\hline & \multicolumn{3}{|c|}{$\begin{array}{l}\text { Ausência de água } \\
\text { canalizada }\end{array}$} & \multicolumn{3}{|c|}{$\begin{array}{c}\text { Presença de água } \\
\text { canalizada }\end{array}$} \\
\hline Ferro & 9 & 116,43 & 75,83 & 22 & 232,81 & 112,50 \\
\hline Zinco & 9 & 113,85 & 56,78 & 20 & 147,75 & 56,41 \\
\hline Cobre & 11 & 154,55 & 40,50 & 21 & 144,05 & 41,01 \\
\hline
\end{tabular}

$1 p$-valor $<0,05$

M: média; DP: desvio-padrão.

\section{I S C U S S Ã O}

O estado nutricional da criança é fortemente influenciado pela condição socioeconômica, sendo também importantes os fatores ligados às características familiares, às condições de habitação e aos cuidados de saúde ${ }^{28}$. Neste estudo, 0 déficit nutricional encontrado foi predominantemente ponderal, destacando que a distribuição dos valores de escores- $Z$, para ambos os índices $P / l$ e E/l, apresentou desvio para a esquerda, expressando presença de risco nutricional na população estudada. Tais resultados seriam esperados, uma vez que as crianças vivem em ambiente desfavorável, caracterizado, principalmente, por condições sanitárias insatisfatórias e por famílias numerosas e de baixo poder aquisitivo.

O ambulatório ASPAS, onde se concentraram as coletas, localiza-se em uma região de características urbanas, hipoteticamente, de fácil acesso pela comunidade. Mesmo assim, uma limitação encontrada neste estudo foi a perda obtida pelo não retorno das crianças às consultas subseqüentes. Como grande parte da amostra foi formada por demanda espontânea, sendo o responsável pela criança informado, na primeira consulta, quanto à ausência de programas de auxílio governamentais e de doação de alimentos, algumas famílias, provavelmente, desmotivadas pela falta desse tipo de assistência, e mesmo orientadas sobre a importância do estudo e dos exames, não retornaram.

As concentrações séricas ou plasmáticas são indicadores viáveis para avaliação de micronutrientes em populações. No entanto, há dificuldades em avaliar as concentrações de minerais em estudos populacionais, principalmente, devido ao uso de métodos invasivos e à não padronização de valores dos pontos de cortes, que, por sua, vez podem aumentar ou reduzir a magnitude dos valores esperados. Dessa forma, a maioria das evidências é baseada em estudos clínicos randomizados e de suplementação29.

A diferença entre os métodos utilizados é outro aspecto a ser discutido. A TXRF-SR, escolhida para o presente estudo, é de alta sensibilidade, e permite a determinação de múltiplos elementos em uma única mensuração, utilizando uma pequena quantidade de material|18-20. Tais características são extremamente vantajosas, principalmente, do ponto de vista ético, uma vez que tornam o processo menos invasivo, quando a amostra é composta por crianças, como neste trabalho. Além desses aspectos, o tempo de mensuração de cada amostra é de, aproximadamente, 5 minutos, o que é importante em qualquer estudo, e o uso direto da radiação na mensuração é uma forma de evitar que a amostra sofra algum tratamento químico, que, conseqüentemente, reduz o risco de contaminação ${ }^{20}$. Todos esses atributos fazem com que a TXRF tenha grandes vantagens sobre outros métodos. Por fim, é importante destacar, que os elementos ferro, zinco e cobre, analisados neste estudo, são aqueles com melhor sensibilidade pelo método.

Quanto aos resultados obtidos em relação às concentrações séricas dos minerais, constata-se uma tendência na população de estudo de teores séricos médios de zinco inferiores aos observados em outros estudos. Em pesquisa realizada em Bangladesh, com crianças com média de idade de 30 meses, os valores médios de zinco no grupo de crianças saudáveis foram de 176 , desvio-padrão (DP) $=98 \mu \mathrm{g} / \mathrm{dL}(\mathrm{n}=38)$, superior ao 
achado desta pesquisa. Numa investigação realizada na Turquia ${ }^{30}$ para comparar os valores séricos de zinco, cobre e ferro entre crianças saudáveis e crianças infectadas com Giardia lambia, constata-se que os teores séricos médios de zinco entre as crianças saudáveis ( $M=145,20$, $\mathrm{DP}=9,13 \mu \mathrm{g} / \mathrm{dL} ; \mathrm{n}=45$ ) também foram superiores aos observados no presente estudo. Em adição, o valor médio das concentrações séricas de cobre foi similar, e de ferro inferior ao deste estudo.

Apesar de bastante documentada a importância do zinco no crescimento linear infantil, não foi encontrada uma correlação significante entre os valores séricos de zinco e os valores de escores$Z$ para o índice E/l. Outros autores encontraram resultados semelhantes ${ }^{31,32}$. Nesses estudos também foi observada uma freqüência reduzida de déficit estatural, o que pode ter influenciado a não associação entre zinco e valores dos escores- $Z$ para E/l. Além disso, o déficit estatural resulta de um processo caracterizado pela redução da freqüência de eventos de crescimento, que pode ter início na vida uterina, e não, necessariamente, refletir o momento atual ${ }^{33}$. Já o déficit ponderal, ou emagrecimento, que foi relativamente alto neste estudo $(28,4 \%, n=29)$, reflete mais as condições atuais, tendo como causas diretas a ingestão inadequada (quantidade e qualidade), e a alta incidência de doenças diarréicas ${ }^{33,34}$, presente em mais de 50,0\% da amostra.

As crianças com relato de diarréia no mês anterior à primeira consulta no estudo, apresentaram médias de concentrações séricas de ferro, zinco e cobre inferiores àquelas sem episódio, sendo apenas significantes para os níveis médios de zinco (Tabela 3). As altas taxas de diarréias estão relacionadas com perdas intestinais de zinco, as quais, acrescidas de uma dieta com baixo teor e disponibilidade desse mineral, típica de países em desenvolvimento, só aumentam a reincidência da doença, estabelecendo o ciclo entre a infecção e a deficiência ${ }^{13}$. A ação benéfica da suplementação de zinco sobre as taxas e a severidade da diarréia já é bem documentada ${ }^{12}$. Estudos mais recentes têm associado a ação da suplementação de zinco combinado a outros minerais, como ferro e cobre. A suplementação de zinco e ferro fol associada significantemente com taxas baixas de diarréia severa ${ }^{10}$. Patel et al. ${ }^{16}$ verificaram que a suplementação de zinco e cobre no tratamento da diarréia foi responsável pela redução de $8 \%$ nos custos de hospitalização e $6 \%$ na redução de custos provenientes de antibióticos, além dos efeitos benéficos nas taxas de complicações e mortalidade.

A incidência de doenças infecciosas na infância é um problema de saúde crucial em países em desenvolvimento, particularmente nas áreas desfavorecidas, nas quais as condições de saneamento são insatisfatórias, as prevalências de déficit nutricional são elevadas, e a oferta de tratamentos, em sua maioria, é inadequada, de modo que a soma desses fatores acarretaria o aumento da severidade e da duração das infecções ${ }^{34}$. Entre essas, a diarréia se destaca como a maior causa de morbidade e mortalidade ${ }^{16}$.

\section{O N C L U S Ã O}

Com base nos resultados, observou-se que episódios de diarréia podem comprometer os valores séricos de zinco, não sendo observada associação significante entre as concentrações de ferro, zinco e cobre e os índices antropométricos estudados. Por fim, a elaboração de programas de intervenção educativos sobre cuidados básicos de saúde e alimentação saudável, teria uma importante contribuição na prevenção e no controle de tais deficiências na amostra estudada.

\section{A GRADECIMENTOS}

À Sociedade Química Fina para o Combate de Doenças Tropicais, que coordena o projeto Vila Rosário, pelo financiamento do material utilizado na coleta de sangue, bem como ao apoio de funcionários do ambulatório ASPAS, em Vila Rosário. 
168 | C.V.D. BORGES et al.

\section{REFERÊ NCIAS}

1. World Health Organization. Child Health Research: a Foundation Improving Child Health. Department of Child and Adolescent Health and Development; 2002. Available from: http:www.who.int/en/

2. Batista Filho $M$, Rissin A. A transição nutricional no Brasil: tendências regionais e temporais. Cad Saúde Pública. 2003; 19(Suppl 1):181-91.

3. United Nations Children's Found. World hunger series 2006: hunger and learning. Vitamin \& mineral deficiency: a global progress report. 2003. [cited 2005 Jul 31]. Available from: www.unicef. org/lac/world_hunger_series_2006_full(1).pdf

4. Black R. Micronutrient deficiency: an underlying cause of morbity and mortality [Editorial]. Bull World Health Org. 2003; 81(2):79.

5. Umesh KMD, Abhavna MSC. Adverse effects of poor micronutrient status during childhood and adolescence. Nutr Rev. 2002; 60(5 Suppl 2):84-90.

6. Mahalanabis D, Bhan, MK. Micronutrients as adjunct therapy of acute illness in children: impact on the episode outcome and policy implications of current findings. Br J Nutr. 2001; 85(Suppl 2):151-8

7. Brutta ZA, Black RE, Brown KH, Gardner JM, Gore $S$, Hidayat AM, et al. Prevetion of diarrhea and pneumonia by zinc supplementation in children in developing countries: pooled analysis of randomized controlled trials. J Pediatr. 1999; 135(6):689-97.

8. Salgueiro MJ, Zubillaga MB, Lysionek AE. The role of zinc in the growth and development of children. Nutrition. 2002; 18(6):510-9.

9. Bhandari N, Bahl R, Taneja S. Effect of micronutrient suplementation on linear growth of children. Br J Nutr. 2001; 85(Suppl.2):131-7.

10. Baqui AH, Zaman K, Persson LA, Arifeen SE, Yunus $M$, Begum N, et al. Simultaneous weekly supplementation of iron and zinc is associated with lower morbidity due to diarrhea and acute lower respiratory infection in Bangladeshi infants. J Nutr. 2003; 133(12):4150-7.

11. Singh M. Role of micronutrients for physical growth and mental development. Indian J Pediatrics. 2004; 71(1):59-62.

12. Walter CF, Black RE. Zinc and the risck for infections disease. Ann Rev Nutr. 2004; 24:255-75.

13. Baqui $A H$, Black RE, Arifeen SE, Yunus $M$, Chakraborty J, Ahmed $S$, et al. Effect of zinc supplementation started during diarrhoea on morbidity and mortality in Bangladeshi children: community randomised trial. Available from: http://bmj.com/cgi/content/full/325/7372/1059
14. Krause M, Mahan LK, Escott-Stump S. Alimentos, nutrição e dietoterapia. 9a. ed. São Paulo: Roca; 1998.

15. Shils ME, Olson JA, Shike M, Ross AC. Tratado de nutrição moderna na saúde e na doença. 9a. ed. São Paulo: Manole; 2003.

16. Patel $A B$, Dhande LA, Rawat MS. Economic evaluation of zinc and copper use in treating acute diarrea in children: a randomized controlled trial. Cost Eff Res Alloc. 2003; 29(1):7.

17. Fisberg M, Naufel CCS, Braga JAP. National prevalence of anaemia in pre school Brazil: 10 Capitals Survey. Ann Nutr Metab. 2001; 45(Suppl.1):450.

18. Anjos MJ, Costa ACM, Moreira S, Lopes RT, Jesus EFO. Analysis of mineral water from Brazil using total reflection $\mathrm{x}$-ray fluorescence by synchroton radiation. Spectrochimica Acta Part B. 2003; 58(12):2199-204.

19. Hernández-Carabalho EA, Marcó-Parra LM. Direct analysis of blood serum by total reflection $x$-ray fluorescence spectrometry and application of an artificial neural network approach for cancer diagnosis. Spectrochimica Acta Part B. 2003; 58:2205-13.

20. Costa RSS, Carmo MGT, Saunders C, Lopes RT, Jesus EFO, Simabuco SM. Trace elements content of colostrum milk in Brazil. J Food Comp Anal. 2002; 15(1):27-33.

21. Costa-Neto C. Vila Rosário: o resgate de uma sociedade pela ciencia, pela tecnologia, pelo trabalho e pela compreensão. Rio de Janeiro: Cálamo Produção Editorial; 2002.

22. Monteiro CA. A dimensão da pobreza, da desnutrição e da fome no Brasil: implicações para políticas públicas. Trabalho apresentado no Seminário Especial Fome e Pobreza pelo Instituto Nacional de Altos Estudos; 2003 [acesso em set 2003]; Rio de Janeiro. Disponível em: http:// forumnacional.org.br

23. Roche AF. Antropometry and ultrasound. In: Roche AF, Heymsfield SB, Lohman TG, editors. Human body composition. Champaign: Humam kinetics; 1996.

24. World Health Organization. The use and interpretation of antropometry physical status: the use and interpretation of antropometry: report of a WHO expert committee. Geneva; 1995. WHO Technical Report Series 854.

25. Nakamura $\mathrm{NH}$. Valores laboratoriais e funcionais normais. In: Carvalho WB, Matsumoto T, Hirschheimer MR. Terapia intensiva pediátrica. São Paulo: Atheneu; 1989.

26. Villalpando S, Garcia-Guerra A, Ramirez-Silva Cl, Mejía-Rodrigues F, Chem GM, Shamah-Levy T, et 
al. Iron, zinc and iodice status in mexican children under 12 years and women $12-49$ years of age. A probabilistic national survey. Salud Publica de México. 2003; 45(Suppl 4):520-9.

27. Milne DB. Copper intake and assessment of copper status. Am J Clin Nutr. 1998; 67(5 Suppl): 1041-5.

28. Fernandes BS, Jerônimo ML, Leone C. Características familiares e cuidados e condições de saúde das crianças: seu papel no risco de desnutrição protéico-calórica. Pediatria. 1996; 18(2):65-74.

29. Bhan MJ, Sommerfelt $H$, Strand T. Micronutrient deficiency in children. Br J Nutr. 2001; 85(Suppl 2):199-203.

30. Ernan P, Yereli K, Kurt Ö, Balcioglu IC, Onag A. Serological levels of zinc, copper and iron elements among Giardia Lamblia infected children in turkey. Pediatr Int. 2002; 44:286-8

31. Hautvast JL, Tolboom JJM, Kafwembe EM, Musonda M, Mwanakasale V, Staveren WAV, et al.
Severe linear growth retardation in rural Zambian children: the influence of biological variable. Am J Clin Nutr. 2000; 71(2):550-9.

32. Penny ME, Marin RM, Duran A, Peerson JM, Lanata CF, Lönnerdal B, et al. Randomized controlled trial of effect of daily supplementation with zinc or multiple micronutrients on the morbidity, growth, and micronutrient sstatus of young Peruvian children. Am J Clin Nutr. 2004; 79(3):457-65.

33. Monte CMG. Desnutrição: um desafio secular à nutrição infantil. J Pediatria. 2000; 76(Suppl 3): 285-97.

34. Stephensen CB. Burden of infection on growth failure. J Nutr. 1999; 129(2 Suppl):534-8.

Recebido em: 20/10/2005

Versão final reapresentada em: 7/8/2006 Aprovado em: 3/10/2006 
